\title{
Precision mixology challenge
}

\author{
Juris Meija ${ }^{1}$
}

(C) Crown Copyright in right of Canada 2015

We would like to invite you to participate in the Analytical Challenge, a series of puzzles to entertain and challenge our readers. This special feature of "Analytical and Bioanalytical Chemistry" has established itself as a truly unique quiz series, with a new scientific puzzle published every other month. Readers can access the complete collection of published problems with their solutions on the ABC homepage at http://www. springer.com/abc. Test your knowledge and tease your wits in diverse areas of analytical and bioanalytical chemistry by viewing this collection.

In the present challenge dilution is the topic. And please note that there is a prize to be won (a Springer book of your choice up to a value of $€ 100$ ). Please read on...

\section{Meet the challenge}

To perform a 100-fold dilution of a stock solution, for example, one can take $1 \mathrm{~g}$ of that solution and dilute it to $100 \mathrm{~g}$ in a separate container. Alternatively, one can perform a two-step serial dilution: first by taking $10 \mathrm{~g}$ of the stock and diluting it to $100 \mathrm{~g}$, then followed by another dilution of the diluted stock (10 g to $100 \mathrm{~g})$. Why would we do that? Because digital balances provide mass estimates with an uncertainty that barely varies with mass of the object. For example, a threedecimal-digit balance which is designed to weigh objects from 1 to $100 \mathrm{~g}$ will give results with a precision of $\pm 0.002 \mathrm{~g}$ for objects weighing from 1 to $100 \mathrm{~g}$. The same could be said

Juris Meija

juris.meija@nrc.ca

1 Measurement Science and Standards, National Research Council Canada, 1200 Montreal Road, Ottawa, ON K1A 0R6, Canada about rulers for length measurement. Hence, we can weigh both $1 \mathrm{~g}$ and $10 \mathrm{~g}$ solutions to the same $\pm 0.002 \mathrm{~g}$ precision with a digital balance and, therefore, the weighing of a $10 \mathrm{~g}$ sample can be done to a 10 times better relative precision than weighing of a $1 \mathrm{~g}$ sample. If the number of intermediate dilution steps is kept small, we have to weigh small amounts of the stock solution, and this can produce large relative errors. If, on the other hand, the number of intermediate dilution steps is large, we are performing too many weighings, which will inflate the overall uncertainty. Surely there must be a balance between these two extremes, which is the topic of this Challenge.

\section{The challenge}

Alice has a standard solution with $3000 \mu \mathrm{g} / \mathrm{g}$ mass fraction of cadmium and she needs to dilute this solution six times using the above-described digital balance.

What strategy should Alice take to obtain the $500 \mu \mathrm{g} / \mathrm{g}$ solution of cadmium with the best possible uncertainty?

We invite our readers to participate in the Analytical Challenge by solving the puzzle above. Please send the correct solution to abc-challenge@springer.com by February 1, 2016. Make sure you enter "Precision mixology challenge" in the subject line of your e-mail. The winner will be notified by e-mail and his/her name will be published on the "Analytical and Bioanalytical Chemistry" homepage at http://www. springer.com/abc and in the journal (volume 408/issue 12) where readers will find the solution and a short explanation.

The next Analytical Challenge will be published in 408/7, March 2016. If you have enjoyed solving this Analytical Challenge you are invited to try the previous puzzles on the $A B C$ homepage. 